\title{
Insulin Injection Technique is Negatively Correlate to Short- and Long-run Glycemic Control in Type 2 Diabetic Patients with Long-Acting Insulin Analogue
}

\section{Yan Cheng}

Yancheng third people's hospital

Qing-he Li

Yancheng third people's hospital

Fen-di Yi

Yancheng third people's hospital

Li-ping Chen

Yancheng third people's hospital

Lei Yuan

Yancheng third people's hospital

Ji-qiang Yan

Yancheng third people's hospital

\section{Lan Gao}

Yancheng third people's hospital

Yu -xia Qi

Yancheng third people's hospital

\section{Qin Sun}

Yancheng third people's hospital

Fu-wan Ding ( $\square$ dingfuwan@163.com )

Yancheng third people's hospital

\section{Dong-ping Wang}

Yancheng third people's hospital

\section{Research Article}

Keywords: type 2 diabetes, insulin injection technique, A1c, mean amplitude of 45 glycemic excursion, continuous glucose monitoring

Posted Date: May 20th, 2021

DOI: https://doi.org/10.21203/rs.3.rs-535126/v1 
License: (c) (i) This work is licensed under a Creative Commons Attribution 4.0 International License. Read Full License 


\section{Insulin Injection Technique is Negatively Correlate to Short- and Long-run}

\section{Glycemic Control in Type 2 Diabetic Patients with Long-Acting Insulin Analogue}

Running Title: Insulin injection technique affects glycemic control

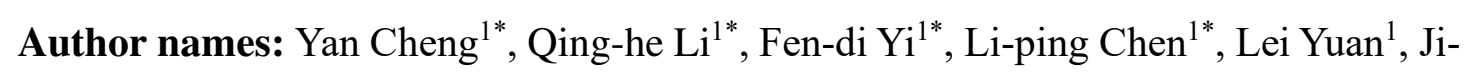
qiang Yan ${ }^{1}$, Lan Gao ${ }^{1}$, Yu-xia Qi ${ }^{1}$, Qin Sun ${ }^{1}$, Fu-wan Ding ${ }^{1}$, and Dong-ping Wang ${ }^{1}$ *the four authors contributed equally to this article.

\section{Author affiliations:}

${ }^{1}$ Department of Endocrinology, Yancheng third people's hospital, Yancheng, China

Address Correspondence to Fu-wan Ding, M.D, Department of Endocrinology, Yancheng third people's hospital, Yancheng, China. No. 166 Yulong West Road, Yancheng, China, 224001.

E-mail: dingfuwan@163.com

Telephone number: +8651566696800 .

\section{Correspondence also should be addressed to Dong-ping Wang, M.D.}

Department of Endocrinology, Yancheng third people's hospital, Yancheng, China.

Address: No. 166 Yulong West Road, Yancheng, China, 224001.

E-mail: Wangdongping0000@126.com

Telephone number: +8651566696800 


\section{Abstract}

Objective: To observe the effects of insulin injection technique (IT) on short- or longrun glycemic control in type 2 diabetic patients (T2D) with long-acting insulin analogue. Methods: This was a single-center, cross-over, observational and open-labled study. Patients with T2D receiving long-acting insulin analogue insulin were enrolled as inpatients. The study period lasting for 5 days including a 1-day screen period and 4day continuous glucose monitoring (CGM) period. During CGM period, patients injected insulin themselves from day 1 to day 2, and patient's insulin IT was given by two independent specialist nurses, with insulin injected by nurses from day 3 to day 4 . The primary endpoint was the correlation between the insulin IT and the mean amplitude of glycemic excursion (MAGE).

Results: A total of 60 diabetic inpatients were recruited and completed the study. The mean score of patients' insulin IT of patients was lower than that of nurses $(p<0.05)$. We observed that the MAGE value was significant different between the two injections period $(\mathrm{P}<0.05)$, and needle reuse and rotation of injection site were negatively correlated to MAGE and HbA1c values, respectively.

Conclusion: Insulin IT was negatively correlation to short- or long-run glycemic control in T2D patients with long-acting insulin analogue therapy.

Key words: type 2 diabetes; insulin injection technique; A1c; mean amplitude of glycemic excursion; continuous glucose monitoring 


\section{Introduction}

Insulin resistance and hyperglycemia are two features of type 2 diabetes (T2D) ${ }^{1}$. If oral antidiabetic agents (OADs) are no longer sufficient to maintain glycemic control, insulin therapy will be a strategy of interest ${ }^{2}$. Available evidences indicates that more than half of T2D Asia population are on insulin therapy ${ }^{3}$, with most of them are prescribed premixed insulin $(77.3 \%)$ for maintaining their glycemic control ${ }^{4-6}$, following by basal (11.8\%) and prandial insulin $(10.9 \%)^{7}$.

Although study demonstrated premixed insulin analogue therapy has beneficial for glycemic variation in Chinese T2D patients ${ }^{8}$. Recently, a pilot study performed in China reporting that only $27 \%$ of type 2 diabetic patients receiving premixed insulin analogue therapy had adequate glycemic control $(\mathrm{HbA} 1 \mathrm{c} \leq 7 \%)^{9}$, which was much lower than those the whole population in China ${ }^{10}$ and the USA population ${ }^{11}$. Incorrect insulin injection technique (IT) is a common phenomenon worldwide, which may be the underline reason for the worsen of glycemic control 12, 13. Lu Yuan, et al. further observed that Chines T2D patients had lower IT, and resuspension, needle reuse and pinching the skin were significantly correlation with glycemic variations $(\mathrm{GV})$ in T2D patients receiving premixed insulin analogue 9 . GV, especially acute postprandial glucose, is an well known risk factor for microvascular and macrovascular complications $^{14}$, and $\mathrm{GV}$ increases circulating cytokines other than chronic glucose concentrations ${ }^{15}$. Which highlight the importance of IT on glycemic control in diabetic patients with insulin therapy.

More than one fifth Chinese T2D received basal and prandial insulin ${ }^{7}$. However, there are rare data regarding the impact of IT on $\mathrm{GV}$ in $\mathrm{T} 2 \mathrm{D}$ patients receiving basal and prandial insulin. Continuous glucose monitoring (CGM) provides a potential opportunity to assess the 24-hrs GV in patients with $\mathrm{T}_{2} \mathrm{D}^{16}$. Therefore, we conducted the single-center, cross-over, observational and open-labled study to observe the relationship between GV and insulin IT in patients with T2D who received long-acting insulin analogue therapy. 


\section{Methods}

This was a s single-center, cross-over, observational and open-labled study. The study protocol and patient consent forms were approved by the Institutional Ethical Committee of Yancheng third people's hospital, Yancheng, China. All procedures performed were in accordance with the ethical standards of Yancheng third people's hospital, and the Helsinki Declaration of 1964 as revised in 2013. Informed consent was obtained from all patients for being recruited in the study.

Between Jan. and Jun. 2019, patients with T2D who used basal and prandial insulin were enrolled as inpatients in Department of Endocrinology, Yancheng third people's hospital, Yancheng, China. The inclusion criteria were 1) Confirmed diagnosis of T2D; 2) patients aged between 18 and 80 years; 3) insulin administered by insulin pen themselves and insulin doses maintained stable for at least 3 months; and 4) patients were willing to perform CGM. The exclusion criteria were 1) patients with serious cognitive dysfunction; 2) patients with ketoacidosis or hyperosmolar state (coma); 3) patients with pregnancy, breast-feeding, or planning to have a baby; 4) patients with poor compliance and irregular eating and exercise; 5) patients with severe retinopathy or other eye problems.

The study period lasting for 5 days including a 1-day screen period and 4-day CGM period. Patients demography data were recorded at day 0 , and fasting serum fasting plasma serum was collected for measurement of $\mathrm{HbA}_{1 \mathrm{c}}$ value on day 1 morning. All recruited patients injected insulin themselves from day 1 to day 2, and patient's insulin IT was given by two independent specialist nurses using a scale containing 15 skillrelated items, with minor modification (Table 1), as previously described ${ }^{9}$. From days 3 to days 4, the same type (unopened) and dose of insulin was delivered by nurses.

During the insulin injection period (from day 1 to day 5), all recruited patients were subjected to a 96-hrs retrospective CGM (Medtronic Incorporated, Northridge, USA), as previously described ${ }^{17,18}$. All patients were instructed to perform self-monitored blood glucose measurements, using OneTouch Ultra Vue blood glucose monitor (LifeScan, Milpitas, CA), before breakfast, lunch, and dinner and before going to bed, 
105 respectively. During the CGM period, three meals per day consisting of a total daily 106 caloric intake of $25 \mathrm{kcal} / \mathrm{kg} /$ day were served at 0700,1100 and 1700 by research nurses, 107 respectively. At the endpoint, CGM data including the mean amplitude of glycemic 108 excursion (MAGE), the 24-hrs mean glucose concentration (MG), the 24-hrs standard 109 deviation of the MG (SD), the incremental area under the curve (AUC) of glucose $>10.0$ $110 \mathrm{mmol} / \mathrm{L}$ and the incremental area over the curve (AOC) of glucose $<3.9 \mathrm{mmol} / \mathrm{L}$ were 111 recorded and analyzed. The primary endpoint was the correlation between the insulin 112 IT and the MAGE. The secondary endpoints were the differences in glycemic profiles 113 between patient and nurse injection period. 


\section{Statistical analysis}

116 The analyses were performed using the SPSS 18.0 (SPSS, Science, Chicago, USA)

117 statistical package. All normal distribution of the data were presented as the means \pm

$118 \mathrm{SD}$, and non-normally distributed data were presented as median $\left(25^{\text {th }}, 75^{\text {th }}\right.$ percentile $)$.

119 Pearson's analysis or Spearman's analysis in nonparametric variable were performed to

120 analyze correlation relationships between two variables. A two-way ANOVA for

121 repeated measurements was used in the comparison of indices between two groups.

122 Multiple linear stepwise regression analysis was performed to identify factors which

123 correlation with MAGE or $\mathrm{HbA}_{1 \mathrm{c}}$. All comparisons were 2-sided at the $5 \%$ significance

124 level. P value less than 0.05 was considered to be statistical significance. 


\section{Results}

Between Jan. and Jun. 2019, a total of 65 patients with T2D who used long-acting insulin analogue were enrolled as inpatients in Department of Endocrinology, Yancheng third people's hospital, Yancheng, China. all recruited subjects completely fulfilled the study, with 1patient was excluded due to unfulfilled of self-injection, and 4 patients were excluded because of missing CGM data $(>30 \%)$. The remaining data from 60 patients (34 males and 26 females) were analyzed at the endpoint. The demographic data were: patients age was $58.4 \pm 14.3$ years, $\mathrm{HbA}_{1 \mathrm{c}}$ value was $8.6 \pm 1.1 \%$, body mass index (BMI) was $23.7 \pm 2.8 \mathrm{~kg} / \mathrm{m}^{2}$ and diabetic duration was $13.2 \pm 7.6$ years, respectively. The duration for using insulin was $7.2 \pm 7.6$ years, with $2.2 \pm 1.4$ injection daily, and the mean insulin dose was $0.4 \pm 0.4 \mathrm{U} / \mathrm{kg} /$ day.

In this study, we assumed scores of insulin IT gained by specialist nurses were 28 points, because they were all trained for diabetic patients care for at least 5 years. We observed that the mean score of patients' insulin IT was significantly lower than those mean score of specialist nurses $(22.3 \pm 3.6$ vs. $28, \mathrm{p}<0.05)$. In addition, there was no differences in score of insulin IT between male and female patients (21.6 \pm 1.7 vs. $23.8 \pm 4.1, \mathrm{p}>0.05)$. In the present pilot study, we expected to see a significant improvement in GV during diabetic patients receiving insulin delivered by specialist nurses compared to those who injection themselves period. Our CGM data showed that the GV, in terms of MAGE, $\mathrm{SD}, \mathrm{CV} \%$, and AUC $>10 \mathrm{mmol} / \mathrm{L}$ in patient injection period were significantly higher than those of nurse injection period $(\mathrm{P}<0.05$, respectively). Although we did not observe significant differences in the $\mathrm{MG}$ and the $\mathrm{AOC}<3.9 \mathrm{mmol} / \mathrm{L}$ between the two injection periods (Table2).

To identify whether score of insulin IT was the independent risk factor for short-run and long-run glycemic control in diabetic patients receiving prandial. Multiple linear stepwise regression analysis showed that insulin IT score was significantly negatively correlated to MAGE $(\mathrm{B}=-0.18, \mathrm{p}<0.05)$, and $\mathrm{HbA1c}(\mathrm{B}=-0.31, \mathrm{P}<0.05)$, controlling for gender, age, BMI, duration with insulin, times of insulin injections daily, doses of insulin daily, duration of diabetes. Of importance, in this study, our data indicated that 
156 subitems of insulin IT, such as needle reuse, were significantly correlated to MAGE

157 value $(r=-0.42, p<0.05)$, and the score of rotation of insulin injection site was negatively 158 correlated to $\mathrm{HbA1c}$ level $(\mathrm{r}=-0.25, \mathrm{P}<0.05)$.

159 


\section{Discussion}

In this pilot study, we observed that nearly half patients with T2D receiving long-acting insulin analogue therapy had their glycemic control. We also found that patients mean IT scores were lower than that of nurses, and the lower IT scores were significantly negatively correlated to the GV, in terms of MAGE, SDBG, and CV\%.

Inject site choice, needle use, insulin suspension, and other profile regarding insulin injection, are common problems affect insulin efficacy in outpatient diabetic patients worldwide ${ }^{12,13}$. In this study, each patient scores of insulin IT were the sum of each subitem score given by two special diabetic nurses according to them performance. we observed that T2D patients with insulin therapy gained dramatically lower IT in the real world, with the scores lost mainly focused on the rotation of injection site and needle reuse.

In this observational study, we observed that only $20 \%$ of $\mathrm{T} 2 \mathrm{D}$ patients had $\mathrm{HbA}_{1 \mathrm{c}}$ less than $7 \% . \mathrm{HbA}_{1 \mathrm{c}}$ is an established index employed for judging long-term glycemic control $^{19-21}$. However, $\mathrm{HbA}_{1 \mathrm{c}}$ value itself can't describe well the glycemic variation, especially acute glucose fluctuation ${ }^{22-24}$. CGM employee is one strength of this study, our data showed that insulin IT not only negatively correlated to $\mathrm{HbA}_{1 \mathrm{c}}$ value, but also negatively correlated to GV. Our findings were in accordance with previous study reporting that patients receiving pre-mixed insulin analogue with lower insulin IT had significantly increase in $\mathrm{GV}$ and $\mathrm{HbA}_{1 \mathrm{c}}$ value ${ }^{9}$.

Unlike premixed insulin analogue, insulin did not need resuspension before injection ${ }^{25}$, ${ }^{26}$. However, other injection problems remain to be resolved. Study revealed that reuse of needles may lead to bad short-run and long-run glycemic control, such as increased in $\mathrm{GV}$ and $\mathrm{HbA}_{1 \mathrm{c}}$ levels ${ }^{13}$, and lipohypertrophy $(\mathrm{LH})^{27}$. Using self-monitoring of blood glucose data, researchers observed that LH was an independent risk factor for the increase in $\mathrm{GV}^{27,28}$. Unfortunately, nearly half of patients with insulin therapy reuse their needles more than once throughout the world ${ }^{12}$. In this study, only $4.2 \%$ patients used their needles once, with most of them had their needles use more than 5 times. Of importance, we found that the needle reuse score was significantly negative related to 
MAGE. Much indices delivered from CGM were used to assess GV, such as MAGE, $\mathrm{SD}$, and $\mathrm{CV} \%$, in pre- or onset diabetic patients ${ }^{29-31}$, of which, there exist a high degree of correlation between SD and MAGE ${ }^{32,33}$. Interestingly, our data also revealed that the score of needle reuse was negatively correlated to SD.

193 Rotate of injection site is one of the independent risk factor for induction of $\mathrm{HbA}_{1 \mathrm{c}}$ level, the underline mechanism may partially be the reason of the $\mathrm{LH}^{12,13,34,35}$. In this study, we observed that patients with insulin with lower rotation injection site score had significantly increase in MAGE, and $\mathrm{HbA}_{1 \mathrm{c}}$ value, which was slightly different to previous study reporting that score of rotation of injection site was negative correlation with $\mathrm{HbA}_{1 c}$ value in patients with premixed insulin analogue, rather than MAGE 9 Future studies identifying the relationship between score of rotation of injection site and $\mathrm{HbA}_{1 \mathrm{c}}$ or MAGE are warranted. Lifted a skinfold is most important in the past decade during insulin injection. However, the score of lifted a skinfold of insulin IT may be not importance as before, because $4 \mathrm{~mm}$ needle was used predominately nowadays in China. In this study, all recruited patients lifted their skinfold well. Several limitations should be addressed in this study. First, the sample size was modest; Second, it was an observational study, not a perspective study, Third, the study population may not be the same as other geography. In conclusion, our data indicates that insulin IT was negatively correlation to short-or long-run glycemic control in T2D patients with long-acting insulin analogue therapy in Chinese population. 


\section{Acknowledgements}

212 This research was funded by Science and Technology Support Program of Jiangsu

213 Province (CN) (No. BL2014010).

214

\section{Authors' Contributions Statement}

216 Y. C., and QH. L. contributed to the conception and design of the study. FD. Y., LP. C., 217 and L. Y. conducted the study and collected data. JQ. Y., L. G., YX. Q., and Q. S. 218 contributed to the data analysis. FW. W., and DP. W. prepared and finally approved the 219 manuscript.

\section{Data availability}

222

None.

\section{Declaration of conflict of interest:}




\section{References}

1. Ferrannini E, Gastaldelli A, Miyazaki Y, Matsuda M, Mari A, DeFronzo RA. Beta-cell function in subjects spanning the range from normal glucose tolerance to overt diabetes: A new

3. Guo XH, Yuan L, Lou QQ, Shen L, Sun ZL, Zhao F, Dai X, Huang J, Yang HY, Chinese

8. Huang $Y$, Heng C, Wei J, Jing X, Wang X, Zhao G, Hou J, Liu Q, Jiao K. Influencing factors

9. Yuan L, Li F, Jing T, Ding B, Luo Y, Sun R, Wang X, Diao H, Su X, Ye L, Ma J. Insulin injection technique is associated with glycemic variability in patients with type 2 diabetes. Diabetes

11. Suh DC, Choi IS, Plauschinat C, Kwon J, Baron M. Impact of comorbid conditions and therapy : research, treatment and education of diabetes and related disorders. 2018;9:2347-2356 Xu Y, Wang L, He J, Bi Y, Li M, Wang T, Wang L, Jiang Y, Dai M, Lu J, Xu M, Li Y, Hu N, Li J, Mi S, Chen CS, Li G, Mu Y, Zhao J, Kong L, Chen J, Lai S, Wang W, Zhao W, Ning G, China Noncommunicable Disease Surveillance G. Prevalence and control of diabetes in chinese adults. Jama. 2013;310:948-959 race/ethnicity on glycemic control among the us population with type 2 diabetes, 1988 1994 to 1999-2004. Journal of diabetes and its complications. 2010;24:382-391

Frid AH, Hirsch LJ, Menchior AR, Morel DR, Strauss KW. Worldwide injection technique questionnaire study: Population parameters and injection practices. Mayo Clinic proceedings. 2016;91:1212-1223

13. Frid AH, Hirsch LJ, Menchior AR, Morel DR, Strauss KW. Worldwide injection technique 
questionnaire study: Injecting complications and the role of the professional. Mayo Clinic proceedings. 2016;91:1224-1230

14. Nakagami T. Hyperglycaemia and mortality from all causes and from cardiovascular disease in five populations of asian origin. Diabetologia. 2004;47:385-394

15. Esposito K, Nappo F, Marfella R, Giugliano G, Giugliano F, Ciotola M, Quagliaro L, Ceriello A, Giugliano D. Inflammatory cytokine concentrations are acutely increased by hyperglycemia in humans: Role of oxidative stress. Circulation. 2002;106:2067-2072

16. Li FF, Liu BL, Yan RN, Zhu HH, Zhou PH, Li HQ, Su XF, Wu JD, Zhang DF, Ye L, Ma JH. Features of glycemic variations in drug naive type 2 diabetic patients with different hba1c values. Scientific reports. 2017;7:1583

17. Li FF, Fu LY, Zhang WL, Su XF, Wu JD, Sun J, Ye L, Ma JH. Blood glucose fluctuations in type 2 diabetes patients treated with multiple daily injections. Journal of diabetes research. 2016;2016:1028945

18. Li FF, Xu XH, Fu LY, Su XF, Wu JD, Lu CF, Ye L, Ma JH. Influence of acarbose on plasma glucose fluctuations in insulin-treated patients with type 2 diabetes: A pilot study. International journal of endocrinology. 2015;2015:903524

19. Retinopathy and nephropathy in patients with type 1 diabetes four years after a trial of intensive therapy. The diabetes control and complications trial/epidemiology of diabetes interventions and complications research group. The New England journal of medicine. 2000;342:381-389

20. Intensive blood-glucose control with sulphonylureas or insulin compared with conventional treatment and risk of complications in patients with type 2 diabetes (ukpds 33). Uk prospective diabetes study (ukpds) group. Lancet. 1998;352:837-853

21. The effect of intensive treatment of diabetes on the development and progression of long-term complications in insulin-dependent diabetes mellitus. The diabetes control and complications trial research group. The New England journal of medicine. 1993;329:977986

22. Del Prato S. In search of normoglycaemia in diabetes: Controlling postprandial glucose. International journal of obesity and related metabolic disorders: journal of the International Association for the Study of Obesity. 2002;26 Suppl 3:S9-17

23. Nathan DM, Kuenen J, Borg R, Zheng H, Schoenfeld D, Heine RJ. Translating the a1c assay into estimated average glucose values. Diabetes care. 2008;31:1473-1478

24. Zhou J, Mo Y, Li H, Ran X, Yang W, Li Q, Peng Y, Li Y, Gao X, Luan X, Wang W, Xie Y, Jia W. Relationship between hba1c and continuous glucose monitoring in chinese population: A multicenter study. PloS one. 2013;8:e83827

25. Omori K, Kawamura $T$, Urata $M$, Matsuura $M$, Kusama $M$, Imamine $R$, Watarai $A$, Nakashima E, Umemura T, Hotta N. Effect of re-coaching on self-injection of insulin in older diabetic patients - impact of cognitive impairment. Diabetes research and clinical practice. 2017:130:34-42

26. Jehle PM, Micheler C, Jehle DR, Breitig D, Boehm BO. Inadequate suspension of neutral protamine hagendorn (nph) insulin in pens. The Lancet. 1999;354:1604-1607

27. Ji J, Lou Q. Insulin pen injection technique survey in patients with type 2 diabetes in mainland china in 2010. Current medical research and opinion. 2014;30:1087-1093

28. Blanco M, Hernandez MT, Strauss KW, Amaya M. Prevalence and risk factors of 
lipohypertrophy in insulin-injecting patients with diabetes. Diabetes \& metabolism. 2013;39:445-453

29. Fabris C, Facchinetti A, Sparacino G, Zanon M, Guerra S, Maran A, Cobelli C. Glucose variability indices in type 1 diabetes: Parsimonious set of indices revealed by sparse

30. Fabris C, Facchinetti A, Fico G, Sambo F, Arredondo MT, Cobelli C. Parsimonious

33. Rodbard D. Increased glycemic variability at the onset and during progression of type 2

34. Wang W, Guo X, Shen G, Bai G, Wei Z, Liu J, Hirsch L, Strauss K. Skin and subcutaneous Prevalence, risk factors, insulin consumption, and clinical impact. Diabetes technology \& therapeutics. 2017;19:61-67 
343 Table 1 The items and scores of insulin injection technique

344 Table 2 The 24-hrs glucose profiles between the two different injection groups 345 346 
Table 1 The items and scores of insulin injection technique

\begin{tabular}{|c|c|}
\hline Items & Scores \\
\hline Injection at indicated time & 2 \\
\hline Yes & 2 \\
\hline No & 0 \\
\hline Warming up to room temperature before injection & 2 \\
\hline \multicolumn{2}{|l|}{ Yes } \\
\hline$>30 \mathrm{~min}$ & 2 \\
\hline$<30 \min$ & 1 \\
\hline No & 0 \\
\hline Checking insulin (dosage and liquid) before injection & 2 \\
\hline Yes & 2 \\
\hline Partly & 1 \\
\hline No & 0 \\
\hline Attaching a pen needle & 2 \\
\hline Correct & 2 \\
\hline Incorrect & 0 \\
\hline Priming before injection & 2 \\
\hline Yes & 2 \\
\hline No & 0 \\
\hline Inspection of injection sites & 2 \\
\hline Yes & 2 \\
\hline No & 0 \\
\hline Rotation of injection sites & 2 \\
\hline Correct & 2 \\
\hline Incorrect & 0 \\
\hline Yes & 2 \\
\hline Correct & 2 \\
\hline Incorrect & 1 \\
\hline No & 0 \\
\hline Pinching the skin & 2 \\
\hline Yes & 2 \\
\hline No & 0 \\
\hline Needle entry angle & 2 \\
\hline Correct & 2 \\
\hline Incorrect & 0 \\
\hline The time(s) the pen needle under the skin & 2 \\
\hline$>10$ & 2 \\
\hline $5-10$ & 1 \\
\hline$<5$ & 0 \\
\hline Pulling needle out while holding dose knob & 2 \\
\hline Yes & 2 \\
\hline No & 0 \\
\hline
\end{tabular}




\begin{tabular}{ll}
\hline Needle reuse (times) & 2 \\
1 & 2 \\
$2-5$ & 1 \\
$>5$ & 0 \\
Insulin (opened and unopened) storage & 2 \\
Yes & 2 \\
Partly & 1 \\
No & 0 \\
Total scores & 28 \\
\hline
\end{tabular}
348

349 
350 Table 2 The 24-hrs glucose profiles between the two different injection groups

\begin{tabular}{llll}
\hline Parameters & Patient & Nurse & P value \\
\hline MG (mmol/L) & $8.4 \pm 3.5$ & $8.2 \pm 1.1$ & 0.63 \\
SD (mmol/L) & $4.2 \pm 3.3$ & $2.5 \pm 2.2$ & 0.02 \\
MAGE (mmol/L) & $6.4 \pm 4.0$ & $4.3 \pm 1.80$ & 0.01 \\
AUC $>10(\mathrm{mmol} / \mathrm{L}$ per day) & $0.5(0.0,0.8)$ & $0.2(0.0,0.3)$ & 0.01 \\
AOC $<3.9(\mathrm{mmol} / \mathrm{L}$ per day $)$ & $0.0(0.0,0.0)$ & $0.0(0.0,0.0)$ & 0.43 \\
\hline
\end{tabular}

MG: the 24-hrs mean glucose concentration, SD: the standard deviation of MG, MAGE: the 24-hrs mean amplitude of glycemic excursion, AUC $>10 \mathrm{mmol} / \mathrm{L}$ : the incremental area under curve of plasma glucose $>10.0 \mathrm{mmol} / \mathrm{L}, \mathrm{AOC}<3.9 \mathrm{mmol} / \mathrm{L}$ : the incremental area over curve of plasma glucose $<3.9 \mathrm{mmol} / \mathrm{L}$. Normal distribution data were presented as mean \pm SD and non-normal distribution data were shown as median $\left(25^{\text {th }}\right.$,

$357 \quad 75^{\text {th }}$ percentile).

358 